\title{
EL IMAGINARIO DEL CANAL Y LA NACIÓN COSMOPOLITA. NICARAGUA, SIGLO XIX. FRANCES KINLOCH. MANAGUA (NICARAGUA): INSTITUTO DE IHNCA-UCA, 2015. 376 PÁGINAS
}

Ethel García Buchard

Recibido: 08/09/2017 Aceptado: 15/09/2017

En este texto la autora realiza una lectura de la historia de Nicaragua a lo largo del siglo XIX e incluso su proyección hasta el presente, a partir de un sueño recurrente: hacer realidad el ansiado proyecto de un moderno canal y así convertir a ese país en una nación cosmopolita. En esta visión el canal atravesaría los poblados y regiones nicaragüenses, de esta forma se une a ambos mares y se acercan estos territorios al "mundo civilizado", convirtiendo en realidad una aspiración condensada en un imaginario compartido y reproducido a lo largo del tiempo como la única vía posible hacia el desarrollo, la modernización y el cambio. Esta una imagen ha estado presente en las variadas coyunturas y ha permeado los diversos proyectos políticos, e incluso ha orientado las luchas de distintos sectores a lo largo del tiempo.

La obra consta de cuatro partes, en la primera, titulada La Independencia y los proyectos nacionales, se analiza el ideario de la independencia y se reconstruye la transición difícil de la colonia al Estado. En la segunda parte la autora explica La difícil organización del Estado, al hacer énfasis en la cruenta iniciación de la vida republicana y las distintas tensiones entre lo nuevo y lo viejo al igual que en los debates suscitados en torno a las elecciones entre caudillos. En la tercera sección, titulada El Canal y la geopolítica, se introducen otros actores, especialmente las relaciones interétnicas, las presiones internacionales enmarcadas en la doctrina Monroe y el Destino Manifiesto, al igual que las tensiones con las repúblicas vecinas, especialmente Costa Rica, en una relación que históricamente ha oscilado entre la idea de hermanos, vecinos o enemigos. Y en la cuarta parte la autora analiza los avatares del proyecto nacional en busca de la nación cosmopolita y el dilema entre el Estado, la República o la Patria Grande como otra constante histórica que traspasa las barreras del tiempo.

Como se mencionó anteriormente, esta travesía se inicia con las novedades y discusiones suscitadas con la Independencia y las distintas propuestas nacionales; en este sentido la autora hace énfasis en la difícil organización del Estado e identifica los debates y analiza las tensiones existentes entre lo viejo y lo nuevo, expresadas en las representaciones y prácticas de los distintos sujetos políticos que se iban visibilizando 
a lo largo del proceso, al igual que los conflictos regionales e internacionales que formaron parte de los procesos de transición hacia la modernidad vividos la sociedad nicaragüense durante este período.

Todo ello en una interacción constante entre lo local, lo regional y lo centroamericano, un enfoque que le otorga un gran valor al estudio, ya que permite entender los conflictos, pero también las alianzas y las negociaciones entre los grupos en los distintos espacios y, al mismo tiempo, se puede constatar que se trata de un momento en el que coexisten varias ideas de patria o nación, las cuales no necesariamente se oponen pero sí dificultan los procesos de construcción nacional estatal.

Con relación a las tensiones locales la autora destaca el peso de los poderes locales y la articulación de redes en las distintas pugnas ocurridas y que han sido caracterizadas como conflictos localistas tradicionales. En este sentido, considera que los procesos electorales en vez de cumplir la función prevista dentro del sistema republicano, constituían instrumentos de poder en manos de las autoridades locales, para comprobar la lealtad de la clientela política o intimidar a los opositores (Kinloch 154). Lo anterior es importante, ya que permite constatar, que, en el caso nicaragüense, al igual que en otras sociedades iberoamericanas de este período, las elecciones y, en general, las distintas prácticas políticas republicanas deben ser consideradas en su relación complementaria con las prácticas propias de las sociedades corporativas, ya que se trata de sociedades en transición donde lo antiguo y lo moderno coexisten. ${ }^{1}$

Sin embargo, también se analiza en el texto los avatares vividos por los nicaragüenses en su búsqueda hacia la centralización del poder y el monopolio de la fuerza legítima como atributos necesarios en todo Estado moderno. Al respecto, la autora considera que la coyuntura abierta a raíz de la guerra civil de 1844 estuvo acompañada de un fuerte proceso de organización de las fuerzas armadas, financiado por un conjunto de nuevas imposiciones fiscales; ${ }^{2}$ sin embargo, esta centralización militar enfrentó la resistencia de los caudillos regionales, quienes a su vez y, en algunos casos, contradictoriamente, eran promotores de reformas constitucionales que generaban controversias en torno al debate sobre los conceptos de pueblo y ciudadano, al igual que la idea de ciudadano propietario y los cambios en la noción de "opinión pública" que, pese a su modernidad, lleva implícita la idea excluyente de opinión ilustrada, reservada para unos pocos (Kinloch 167-171). En este sentido la autora reconstruye a lo largo del texto esa permanente tensión y relación de complementariedad entre lo nuevo y lo viejo en las prácticas políticas de los distintos actores y que forma parte de la cultura política del período.

Algunas de las implicaciones de todo lo anterior es que las divisiones al interior de las elites abrieron diversos cauces a través de los cuales se desbordó el descontento popular; en este contexto, las redes verticales heredadas de la colonia jugaron un papel importante, pero también las prácticas modernas de difusión 
de los principios republicanos, como la impresión de panfletos y la prédica personal entre las masas (Kinloch 172).

En todo este recorrido la autora nos recuerda que en esa búsqueda de viabilidad estatal y necesidad de afirmación de una autoridad fragmentada por las tensiones locales y regionales, acompañada de las presiones populares, siempre estuvo presente esa visión de prosperidad asociada al canal. Esta, al inicio de las luchas republicanas, logró unir temporalmente a las figuras más representativas de los dos bandos políticos rivales: Francisco Morazán y Juan José Aycinena (Kinloch 181), pero también atrajo las ambiciones geopolíticas de Gran Bretaña y puso en evidencia la incapacidad de la elite para afianzar su autoridad.

Si se considera lo anterior, queda claro que la idea moderna de nación y pueblo como sujeto soberano no eran más que referencias intelectuales abstractas y que el concepto de comunidad política heredado de período colonial aún conservaba todo su vigor y reflejaba la existencia de múltiples comunidades heterogéneas representadas por sus cabildos (Kinloch 203).

En la obra se destaca que, desde sus inicios, el proyecto canalero trascendía el ámbito económico y prometía convertirse en un instrumento de pacificación incluso para el istmo centroamericano en el contexto de la construcción del proyecto federal (Kinloch, 185) y, a su vez, es una imagen que se ha ido reproduciendo a lo largo del tiempo y se convierte en bandera de lucha en contextos específicos.

Esta debilidad interna se tradujo en impotencia para asegurar el reconocimiento externo y para defender la integridad del territorio (Kinloch 205); en otras palabras, el mito decimonónico del progreso se encarna en el proyecto canalero y el filibusterismo es percibido como un elemento civilizador e incluso como un factor de estabilidad, una visión compartida por los distintos actores tanto democráticos como legitimistas. Pero, a su vez, se convierte en una fuente de conflicto al complicar las relaciones interétnicas entre las poblaciones del naciente Estado que se expresan en un conjunto de disputas que trascienden hasta el presente.

En el texto también se destaca la persistencia de las lealtades forjadas durante el período colonial tanto en el área administrativa mayor constituida por el Reino de Guatemala como hacia las patrias chicas conformadas en torno a las ciudades principales; una persistencia que también explica que, en el periodo estudiado, el Estado fuera aún una novedad que debía construir sus propias lealtades a costa de la subordinación de una multiplicidad de apegos y fidelidades, en un proceso que generó múltiples conflictos entre las elites regionales (Kinloch 285) y, por lo tanto, incrementó la debilidad interna y la incapacidad para negociar y hacer frente a los intereses canaleros internacionales.

Esta tensión permanente entre dispersión del poder y escasa legitimidad del poder por parte del Estado y la constante presión de los intereses internacionales al igual que un imaginario nacional siempre volcado hacia fuera, el cual se destaca como una constante en la historia de Nicaragua y de Centroamérica en su conjunto, 
son reconstruidos por la autora con una gran cantidad de fuentes, que van desde las visiones y los debates suscitados entre algunos de los principales actores y recogidos por la prensa regional y nacional, hasta las propuestas de los gobiernos en determinados contextos, publicados en la prensa oficial y reproducidos en compilaciones de documentos realizados por historiadores positivistas y que la autora utiliza para reconstruir algunos de los debates e identificar las distintas agendas de los actores, al igual que los documentos generados a partir de las relaciones internacionales y que nos dan cuenta de los intereses geopolíticos de las potencias en torno al canal.

Todas estas fuentes son utilizadas por la autora para realizar un análisis desde un enfoque global donde las relaciones locales y regionales con los poderes estatales dialogan con los intereses geopolíticos y, al mismo tiempo, este conjunto de tensiones converge para construir y reelaborar un imaginario compartido, en el cual el canal y la idea de una nación cosmopolita constituyen los pilares donde descansa el sueño de la sociedad moderna.

\section{Notas}

1 Para una discusión sobre la importancia de las elecciones en las sociedades Iberoamericanas durante la transición de la colonia a la república ver a Annino, Antonio, coord. Historia de las elecciones en Iberoamérica, siglo XIX, México, Fondo de Cultura Económica, 1995 y del mismo autor "El Voto y el siglo XIX desconocido", Istor, Revista de Historia Internacional, núm. 17, 2004, 43-59. Véase también a Hilda Sábato, Coord., Ciudadanía política y formación de las naciones. Perspectivas históricas de América Latina, México, Fondo de Cultura Económica, 1999 y de la misma autora La política en las calles. Entre el voto y la movilización (1862-1880), Buenos Aires, Universidad Nacional de Quilmes, 2004. Para el caso centroamericano véase a Avendaño Rojas, Xiomara, coord., "Historia electoral en Centroamérica. Elecciones, Organizaciones politicas y ciudadanía (siglos XIX y XX), Managua, Lea Grupo Editorial, 2011. Véase también, de la misma autora, la obra titulada Centroamérica, entre lo antiguo y lo moderno. Institucionalidad, ciudadanía y representación política, 1808-1838, Castelló de la Plana, Publicacions de la Universitat Jaume I, 2009.

2 Se han realizado diversos estudios sobre el ejército y la fiscalidad como atributos necesarios en la configuración de un Estado nacional, es el caso de los estudios incluidos en la obra colectiva titulada Latin American Bureaucracy and the State Buidling (1780-1860), editada por Juan Carlos Garavaglia y Juan Pro Ruiz y publicada por Cambridge Sholars Publishing en 2013.

Ethel García Buchart. Costarricense. Doctora en Historia por la Universidad de Costa Rica, catedrática y docente jubilada de la Universidad de Costa Rica e investigadora ad honoren del Centro de Investigación en Identidad y Cultura Latinoamericana (CIICLA).

Contacto: ethelgarciabuchard@gmail.com

ORCID: 0000-0002-8759-3632 